\title{
Modernidad y servicios públicos en la conformación del espacio urbano del siglo XIX
}

\author{
Eulalia Ribera Carbó*
}

Resumen

El caso concreto de la ciudad de Orizaba se inserta en una reflexión general sobre cómo la innovación, la distribución y la organización administrativa de los servicios públicos y sus infraestructuras reflejan y determinan a la vez formas y funcionamientos de las ciudades que se transforman en el siglo XIX.
Abstract

The study of the city of Orizaba is part of a general reflection about how the innovation, distribution and administrative organization of public services and their infrastructures determine simultaneously forms and function of the cities which were transformed in the nineteenth century.
Palabras clave:

Orizaba, servicio público, infraestructura urbana, administración, organización territorial.
Fecha de recepción: junio de 2000

Fecha de aceptación: octubre de 2000

*Profesora-investigadora titular del Instituto de Investigaciones Dr. José María Luis Mora, donde actualmente trabaja en un proyecto sobre la estructura de las ciudades mexicanas en el siglo XIX. Correo electrónico: eribera@institutomora.edu.mx 
$\mathrm{O}$ rizaba no era tan diferente, tenía, como todas las ciudades, una personalidad singular moldeada por las características naturales del sitio en que se había ido levantando desde el siglo XvI; moldeada también por la situación geográfica que le dio una posición estratégica sobre el territorio del país y, por supuesto, producto de los procesos socioeconómicos y políticos de su propia historia. Pero aun con sus singularidades importantes, y desde luego interesantes, en el siglo XIX Orizaba no era tan distinta en un panorama urbano mexicano, que podríamos inclusive ampliar mucho más allá de las fronteras nacionales.

En toda la América española, después del "esplendor" dieciochesco que las reformas del despotismo borbónico y el crecimiento de finales de siglo habían producido en las ciudades de los circuitos económicos más activos, vino un tiempo de letargo y abandono que dejó su pátina implacable en edificios, plazas y calles. Una vez terminadas las guerras de independencia y hasta mediar la centuria, las ciudades permanecieron con los entramados viarios prácticamente intactos, no se hicieron obras constructivas relevantes ni se acicaló la fachada urbana, y los agotados fondos de los erarios municipales apenas sirvieron para ir paliando los desperfectos más urgentes de corregir. Pero a partir de entonces, y en unas estructuras físicas poco alteradas, empezaron poco a poco a darse cambios que apuntaban hacia lo que, a partir del último tercio del siglo XIX, serían las transformaciones de cara a un mundo organizado por la burguesía. Eran cambios en el uso social de los espacios ur- banos. Eran novedosas modas impuestas por la apertura comercial. Eran otras formas de concebir y administrar el gobierno ciudadano. Eran, ni duda cabe, los primeros esfuerzos de los grupos con capacidad de actuar sobre el terreno de la ciudad, para crear una nueva imagen urbana, más suntuosa y acorde con las exigencias de los idearios políticos que, nacidos de la revolución francesa, acabaron triunfando en todas partes. ${ }^{1}$

Los servicios públicos y sus infraestructuras son generadores y a la vez expresión de algunos de esos cambios, y en tal sentido desempeñan un papel importante en la estructuración de las ciudades de la modernidad decimonónica.

\section{EL AGUA}

Orizaba es nuestro ejemplo y sirve bien. Al empezar el siglo XIX, la húmeda Pluviosilla, que tanta agua veía pasar por ríos y arroyos, no contaba con un sistema hidráulico que permitiera a sus habitantes disfrutar en sus casas de agua limpia y corriente. Los orizabeños sacaban de pozos el precioso líquido para uso doméstico, y los menos afortunados lo acarreaban en cacharros desde los cauces que atravesaban la ciudad. ${ }^{2}$

${ }^{1}$ Sobre el tema de la periodización y las características generales en el desarrollo de las ciudades hispanoamericanas durante el siglo XIX son interesantes los trabajos de Geisse y Halperin; Geisse, "Tres", 1986; Halperin, "Ciudades", 1980.

2 Arróniz, Ensayo, 1980, pp. 301-305. 
El historiador local Joaquín Arróniz habla de que, en 1768 , el entonces dueño del importante molino de la Marquesa, construido en la margen del río Orizaba, quien gozaba de la merced para aprovechar las aguas fluviales, permitió que los frailes carmelitas canalizaran una naranja de agua hasta su convento, y de ella dieran un limón para la casa de una viuda que estaba en lo que después fue hospital, y más tarde, cuartel de San Antonio. ${ }^{3}$ Lo único que se les pedía era que ellos reformaran y repararan la presa de pared y piedras que había más arriba del molino. ${ }^{4}$

Con el tiempo el canal sacaba más agua de la acordada, hecho que no dejó de originar algún pleito, y la repartía a los carmelitas y al hospital, pero también a la factoría de tabaco y a dos fuentes públicas, que al menos un poco de ella acercaban al vecindario del convento.

En 1769 el oratorio de San Felipe Neri también fabricó una cañería desde un manantial al sur de la ciénaga de Tepatlaxco, hasta su imponente edificio en construcción.

Pero lo cierto es que en los albores del ochocientos solamente las dos tuberías de los frailes transportaban el líquido, que apenas era suficiente para sus destinatarios.

${ }^{3}$ En todos los textos decimonónicos que hemos leído se habla de limones, de naranjas, de toronjas, de granos de cebada y de pajas para describir el volumen de agua canalizada. Seguramente los términos simulan el diámetro de las cañerías.

${ }^{4}$ Archivo Municipal de Orizaba (en adelante AMO) ramo Aguas, caja 11/80, año 1861; Arróniz, Ensayo, 1980.
En 1803 don José Joaquín Vivanco, miembro de las "fuerzas vivas" de Orizaba, de familia de cosecheros de tabaco y comerciantes, se dirigió al Cabildo de la ciudad para hacerle una propuesta. Convencido de los efectos nocivos que para el cuerpo y el alma de la gente de la villa tenían las aguas subterráneas sacadas de los pozos, estaba dispuesto a hacer el gasto necesario para introducir agua corriente y limpia hasta la plaza principal. Sólo a cambio de unas cuantas condiciones: que de ahí se le diera gratuitamente al hospital de San Juan de Dios, cuyo aguador trabajaba incansablemente, y se hiciera otro tanto con el hospital de mujeres y el oratorio de San Felipe, que recibía aguas especialmente insalubres; finalmente, que la casa del benefactor contara a perpetuidad, y también sin pago de pensión, con una paja para sí de la que él mismo pondría y cuidaría las cañerías. Toda el agua restante podría ser distribuída y vendida en el vecindario.

En el ofrecimiento de Vivanco, al Ayuntamiento le tocaba la tarea de construir la caja recipiente con el repartidor y la pila, la fuente y las alcantarillas. Había además que arreglarse con el regidor Julián Romanos, propietario del molino de la Marquesa, para que de buena voluntad permitiera que el agua se tomara de su acequia, junto al puente, y en la cantidad de una naranja, ya que era el único lugar del que se podía bajar cómodamente a la plaza. ${ }^{5}$

La idea fue bien recibida, y un mes después, el síndico procurador del co-

5 AMO, ramo Aguas, caja 90/159, año 1885. 
mún había redactado un informe en el que hacía acotaciones sobre la idea original. Era conveniente ampliar la presa que juntaba agua cerca del molino, $y$ en vez de tomar de ella solamente una naranja, que no alcanzaba para cubrir los gastos de fuentes y cañerías, ni para hacer demasiados repartos, resultaría mejor extraer una toronja. Puestos a gastar, convendría extender la obra hasta la cárcel y dos fuentes públicas "embebidas" en una pared sobre la calle Real, que surtirían a los vecinos y darían servicio a la arriería; también construir por cuenta de las arcas públicas la infraestructura para los hospitales, librando así a los feligreses de las limosnas que los superiores de las benéficas instituciones "exigieran con sus ruegos, para la obra nueva".

La toronja tendría 96 granos de cebada para repartir entre las casas, y con que se vendieran 22 en la carrera de la cañería, a 200 pesos cada uno, sería suficiente para reunir los costos de las primeras construcciones. Después, cumplidas las exigencias del señor Vivanco, los demás granos podrían venderse considerando los trabajos de cañería y los costos por la limpieza de la caja de agua, y tal vez con el tiempo, hasta podrían levantarse dos lavaderos públicos para obtener fondos extras para el Ayuntamiento.

En julio, el procurador general de la corporación había leído el expediente con el informe detallado y se lo envió al regidor Manuel Montes de Argüelles. Éste contestó en septiembre mostrándose de acuerdo con las condiciones generales en que debía llevarse a cabo la empresa, y a su vez precisó detalles en algunos renglones. $\mathrm{Al}$ am- pliar la presa para asegurar el abastecimiento de agua al molino y a los drenajes durante el estiaje, quedaría seco el trecho entre la presa y el punto donde el molino restituía el agua; era conveniente, entonces, dejar una "luz" a la presa para que escurriera un hilo de agua suficiente para los pocos vecinos del lugar, quienes podrían recogerla en cacharros.

El uso del agua canalizada por la acequia del molino tenía que ser asegurado por medio de algún mecanismo "solemne" que evitara problemas futuros con otros posibles dueños del establecimiento. En cuanto a los hospitales, también era conveniente fijar de antemano la cantidad. que se les proporcionaría, para que después no se formaran nuevas pretensiones. $Y$ sobre todo, si después de calcular seriamente el proyecto resultaba que las ganancias por la venta anticipada del agua no eran suficientes para dejar un sobrante regular a favor del ilustre Ayuntamiento, la ayuda a los hospitales sólo debería hacerse hasta el límite de lo posible y sin temor a dejarlos privados del beneficio. Ya hallarían ellos la forma de consumar la obra cobrando limosnas.

Por lo visto, el regidor no era en asuntos materiales tan piadoso como otros aparentaban serlo, y tenía una visión más pragmática en las negociaciones de los asuntos terrenales.

Una vez que los vecinos hubieran sido avisados y se presentaran a solicitar fuentes para sus casas, sólo entonces se resolverían las rutas para encaminar más ventajosamente el agua; y sobre todo, no debería construirse un acueducto para darle agua a un solo so- 
licitante de una calle: si acaso, se le vendería el derecho de agua, nada más.

Sin embargo, no es sorprendente que al tiempo que se hacían estas primeras reflexiones ya se hablaba con suficiente certeza de los encañonados que correrían desde la plaza por calles que no por casualidad son las que definían el corazón de la "ciudad española" en ese momento, y el que continuará siendo el núcleo de los orizabeños privilegiados del siglo XIX. ${ }^{6}$

Una última consideración hace el regidor en su documento dirigido al Cabildo, y es en el sentido de que el precio de los granos de agua que llegaría a las casas de los vecinos interesados tendría que ser el mismo para todos, sin importar que unos vivieran más cerca de la fuente repartidora de la plaza, y otros más lejos. Un precio equilibrado evitaría beneficiar a unos y agraviar a otros

Al estar todos de acuerdo, finalmente se iniciaron las diligencias del caso, y en noviembre de 1803, ocho rotulones fijados en los lugares acostumbrados anunciaban a los ciudadanos que, los interesados en tener agua potable y corriente en sus casas, debían concurrir a suscribirse en el oficio del Cabildo en el plazo de un mes. El 13 de abril de 1805 , casi dos años después, se estrenaba la fuente en la plaza de la parroquia, y el público comenzó a disfrutar del agua corriente con la abundancia necesaria "para el abasto de todo el vecindario". Al mismo tiempo, una escritura firmada por la viuda de Julián Romanos, dueño del molino de la Marquesa, hacía la dona-

${ }^{6}$ Ibid. ción del agua de su acequia "firme y valedera para siempre jamás". ${ }^{7}$

El esqueleto de la nueva infraestructura muy pronto fue creciendo y ramificándose. En 1839 había diez fuentes públicas en el casco central de la ciudad y muchas de sus casas contaban ya con el servicio. Para 1846 se empezó a pensar en habilitar un nuevo acueducto para alcanzar a otros barrios, y durante los años subsiguientes se trabajó con interrupciones en los proyectos para tal efecto. ${ }^{8}$

La primera preocupación la ocuparon los barrios de Cocolapan y de la Angostura, seguramente debido al polo de atracción y crecimiento en que se había convertido la fábrica textil inaugurada unos años atrás. El presidente del Ayuntamiento, José Joaquín Pesado, le encargó las nuevas obras a José María Naredo y se recabaron fondos con la venta de algunos sitios del fundo legal de aquellos rumbos. En 1848 fueron inauguradas tres fuentes en la calle Principal, junto al barrio de las Flores. El propio Naredo las describe "con sus elevados chorros saltantes" que daban "una hermosa vista a aquellos lugares".?

En 1850 se acabó de pulir el proyecto, y fueron destinados nuevos gastos para concluir la introducción de agua potable al barrio de la Angostura, que era el barrio del antiguo arenal. Las alcantarillas repartidoras debían estar terminadas antes de que empezaran las lluvias, y a quienes se concedie-

7 Ibid.

${ }^{8}$ Naredo, Estudio, 1898, pp. 231-232; Segura, "Apuntes", 1854, pp. 20-21.

${ }^{9} \mathrm{Baz}$, Historia, 1977; Naredo, Estudio, 1898. 
ran las pajas de agua deberían pagar por la construcción de las alcantarillas y la conservación de los acueductos. ${ }^{10}$

El agua se había convertido en un asunto de importancia indiscutible para el Ayuntamiento, que incrementaba los ingresos de sus arcas, pero que a su vez lo obligaba a gastos ineludibles en constantes obras de construcción y de mantenimiento.

Si comparamos dos planes de arbitrios y presupuestos que tenemos a la mano, preparados por la Comisión de Hacienda del Ayuntamiento para regir en 1858 uno y en 1870 el otro, se hace evidente que hay un aumento importante en los números absolutos de los ingresos obtenidos por las pensiones cobradas a las casas que disfrutaban de agua corriente. Por pajas de agua repartidas, al mismo precio cada una, se cobraba más del doble. Además, se especulaba contar con una buena cantidad extra por derechos de merced a nuevas concesiones. Es notorio, también, que, aunque porcentualmente los gastos que representaba para el Ayuntamiento el ramo de aguas prácticamente no varían, hay un aumento considerable de las cantidades erogadas en las obras materiales realizadas en la infraestructura hidráulica (véase cuadro 1). ${ }^{11}$

Y para confirmarlo no sólo están los números de Hacienda del Ayuntamiento, sino el volumen de obras realizadas por el municipio que señala un aumento en el transcurso del siglo, sobre todo hacia el inicio de su último ter-

10 AMO, ramo Aguas, caja 1/67, año 1850; Baz, Historia, 1977.

11 AMO, ramo Hacienda, caja 9/78, año 1858; caja 32/101, año 1870 . cio, con la construcción de cajas repartidoras de agua, de atarjeas, y en la compostura y limpieza de canales y fuentes públicas. ${ }^{12}$ Además, ante un sistema que cada día se complicaba más, un código de normas que rigiera su funcionamiento se hizo absolutamente necesario.

Los reglamentos de policía de la ciudad son elocuentes al respecto. De dos o tres referencias desperdigadas en las legislaciones de la primera mitad del siglo, y preocupadas más que nada por el ornato y la salubridad, en 1864 y 1868 aparece en ellas una sección entera titulada Aguas, que en varios artículos versa directamente sobre la forma de organizar una estructura de fuentes y cañerías que tenía su primer origen 60 años atrás, y en la que el Ayuntamiento se confirma como el "dueño y señor" del agua orizabeña, y el único capaz de otorgarla y beneficiarse de su concesión. ${ }^{13}$

Aun con estos esfuerzos, el sistema de reparto de agua, a mediados de siglo, se había convertido en un "laberinto" difícil de administrar, en el que encima de la complicación en el tendido de las infraestructuras, había filtraciones en las tuberías de barro, la presa del molino requería de urgentes reparaciones, y muchos dueños de casas compartían sus pajas de agua o las vendían en flagrante estafa a la autoridad. ${ }^{14}$

1.2 AMO, ramo Policía, años 1855-1875.

13 AMO, ramo Policía, caja 3/69, año 1850; caja 26/95, año 1868; caja 14/83, año 1864 .

14 AMO, ramo Estadística, caja $9 / 78$, año 1858; ramo Aguas, caja 9/78, año 1858; ramo Policía, caja 11/80, año 1861 . 


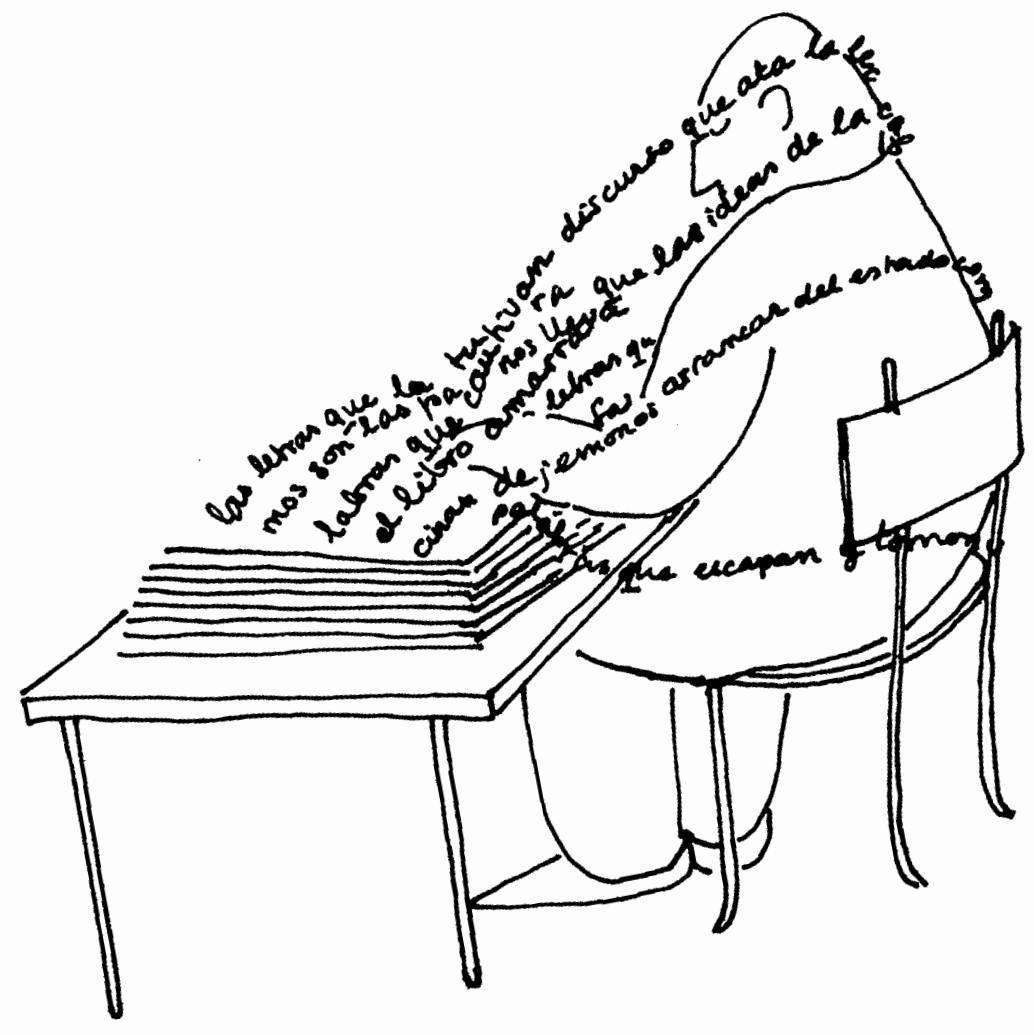


Cuadro 1. Plan de arbitrios y presupuesto de gastos realizado por el Ayuntamiento de Orizaba para regir en los años 1858 y 1870 en el ramo de aguas

\section{Ingresos municipales}

(en pesos)

\begin{tabular}{lrr} 
& \multicolumn{2}{c}{ Años } \\
& 1858 & 1870 \\
Pensión de pajas de agua a cinco y seis pesos cada una & 702 & 1500 \\
Pensión de los molinos por uso de agua para mover sus maquinarias & 200 & 200 \\
Derecho de concesión de uso de agua suponiendo que se otorguen & & \\
diez mercedes en el año & - & 500 \\
Total & 902 & 200 \\
Porcentaje & 3.1 & 3.7
\end{tabular}

\section{Gastos municipales}

(en pesos)

\begin{tabular}{lrr} 
& \multicolumn{2}{c}{ Años } \\
& 1858 & 1870 \\
Sueldos de un maestro de cañería o fontanero y de un peón o ayudante & 414 & 660 \\
Obras y reparaciones en las cañerías y en la presa & 500 & 880 \\
Total & 914 & 1540 \\
Porcentaje & 2.7 & 2.6
\end{tabular}

Fuente: Para 1858, AMO, 9/78, ramo Hacienda, 1858; para 1870, AMO, 32/101, ramo Hacienda, 1870. Elaboración de los cuadros Eulalia Ribera Carbó.

\section{LA LUZ}

Si tepasamos brevemente la historia de la iluminación nocturna de la ciudad, hallaremos que con todas las diferencias propias del caso, ésta presenta grandes analogías con la del agua.

A principios del siglo XIX, como en el caso del agua, un servicio de iluminación callejera tampoco estaba organizado, y Orizaba de noche era una ciudad oscura. Solamente algunas lámparas de barro, con aceite de "nabo" o manteca por combustible, colocadas en las rejas de las ventanas de algunos vecinos, rescataban a las calles de las tinieblas absolutas.

También, como en el caso del agua, fue por la iniciativa de un destacado cosechero y oligarca orizabeño, don José María Mendizábal, que en los años veinte empezó a funcionar el primer sistema de alumbrado público administrado por la municipalidad, consistente en 150 faroles que quemaban aceite de sebo, y que habían sido com- 
prados con donativos de comerciantes de buena posición.

Se adquirieron los barriles suficientes con el aceite de sebo para quemar y las fibras de pabilo necesarias, y se designó a un administrador, a un jefe de resguardo montado y a varios guardias de a pie para poner en marcha la innovación nocturna. ${ }^{15}$

Enseguida la discusión se centró en el importante asunto de sobre quién debía recaer la carga impositiva del nuevo servicio a la comunidad. Unas voces proponían que los comerciantes, los productores de tabaco, y los de trigo y harina solventaran la mayor parte; otras sugerían que se obtuvieran fondos de las funciones de teatro en descargo de las arcas del Ayuntamiento; pero desde un principio se cobraron impuestos a los propietarios de las casas de los vecinos beneficiados por la luz, convenidos de acuerdo al valor de sus edificios. ${ }^{16}$

Hubo quejas y problemas, como siempre, cuando de impuestos se trataba. Algún particular daba lata con los pagos, los presbíteros pedían exenciones para las fincas de alguna orden piadosa, que encima de hacer obra benéfica por los pobres sin recibir ningún auxilio de la autoridad civil, decían, eran castigados con las cuotas para cubrir el servicio. ${ }^{17}$ Cuando la ciudad sufría crisis políticas y económicas solían quedar casas vacías, el precio de los arrendamientos bajaba, y ello hacía que 1826.

15 AMO, ramo Alumbrado, caja 47/46, año

16 AMO, ramo Alumbrado, caja 47/46, año 1826; caja 47/46, año 1827.

17 Ibid., caja 4/70, año 1853. disminuyera automáticamente el número de recibos que entraban al Ayuntamiento por concepto del alumbrado público. ${ }^{18}$

$\mathrm{Y}$ al igual que sucedía con muchos otros, este ramo tenía serias complicaciones por la falta de un padrón completo de las casas que pagaban pensiones, faltaba la numeración y la información sobre su propiedad, su ocupación o su arriendo. Todo ello hacía que los productos por las contribuciones de alumbrado no fueran suficientes, y el Ayuntamiento se viera obligado a erogar cantidades que no se consideraban justas. ${ }^{19}$ El Ayuntamiento se propuso muchas veces levantar el padrón general y detallado de la ciudad, ordenando y corrigiendo la nomenclatura de las calles y los números de las casas, pero las buenas intenciones sólo alcanzaban éxitos parciales.

El 17 de abril de 1856, el gobierno del estado aprobó un Reglamento de alumbrado, redactado por el Ayuntamiento orizabeño para la "conservación y mejora" del ramo. La preocupación se centraba más que nada en la formación urgente de los padrones que facilitaran la distribución y la recaudación de las pensiones. Durante los primeros ocho días del mes de enero de cada año, los regidores encargados de los cuarteles en que se dividía a la ciudad, auxiliados por los jefes de manzana, levantarían el padrón de su cuartel. En él especificarían los nombres de las calles, el número de cada casa, nombre y apellido de los propietarios, el mon1856.

18 Ibid., caja 4/4, año 1854 ; caja $6 / 73$, año 19 Ibid., caja 6/73, año 1856. 
to del arrendamiento comprobado en una copia del último recibo mostrado por arrendatario e inquilino, si estaba habitada o no, o bien, eta ocupada por efectos de comercio o materiales de construcción; si se trataba de una vecindad se anotarían nombres y apellidos de cada inquilino con el monto de la renta que pagaba cada uno.

Así, finalmente, el padrón general facilitaría la recaudación del impuesto y permitiría tener noticia detallada de las calles y casas que carecieran del beneficio de la iluminación, o de aquellas en que fuera imperfecto o insuficiente. Una vez aprobado e impreso se fijaría en los parajes públicos para el conocimiento de los causantes, y se haría circular entre los empleados municipales.

Los contribuyentes tenían, además de la obligación de pagar, también la de presentar al recaudador, entre los días 25 y 30 de cada mes, la noticia de la casa que quedara vacía para poder eximirle del cobro. Si no lo hacían tendrían irremediablemente que pagar la cuota correspondiente, pero si daban noticias falsas, su fraude sería castigado con una buena multa. El último día del mes el recaudador extendería y firmaría los recibos. ${ }^{20}$

No sabemos si los resultados del proyecto cumplieron sus expectativas. La realidad es que hasta entonces, con el paso de los años, el número de luces había ido aumentando modestamente, tanto que, para 1854, casi 30 años después de que las primeras 150 luces se hubieran estrenado, apenas 180 faroles

${ }^{20} \mathrm{Ibid}$. en regular estado adornaban a Orizaba. ${ }^{21}$

Doce serenos y un cabo, encargados también de la seguridad nocturna, se ocupaban del servicio. Encendían los candiles en el momento convenido y hacían sus rondas anunciando la hora con su silbato cada 30 minutos. Se gastaba en lo imprescindible como el aceite que se compraba en la plaza, la mecha, el pabilo, el jabón, y el papel de los recibos. Se pagaban sueldos y el alquiler de un cuarto de depósito para los útiles y, de vez en cuando, se invertía en la compostura de una escalera, se hacían reverberos para que luciera más el alumbrado, se compraban candilejas nuevas o se reponían bombillas y quinqués. ${ }^{22}$

Por ese tiempo un reporte informaba que el alumbrado se hallaba extendido por toda la circunferencia de la ciudad -lo que sin duda se refiere al distrito central- y sin abarcar a los suburbios. Y aunque en 1854 se había dispuesto que el tiempo de iluminación se prolongara hasta el amanecer, lo cierto es que la mejoría en el servicio parece limitada a eso, a unos cuantos faroles más y a alargar las horas de encendido. ${ }^{23}$

En los años sesenta, a los vecinos incluso se los obligaba, en los reglamentos de policía, en la sección de $\mathrm{C}_{0-}$ modidad, ornato y limpieza, a mantener luz en los zaguanes de sus casas si estos

${ }^{21}$ AMO, ramo Policía municipal, caja 4/4, año 1854.

22 AMO, ramo Alumbrado, caja 4/4, año 1854; ramo Policía municipal, caja 4/4, año 1854 .

${ }^{23}$ AMO, ramo Alumbrado, caja 4/4, año 1854 ; ramo Policía urbana, caja 4/70, año 1854. 
permanecían abiertos desde el oscurecer hasta las diez de la noche, hora señalada para cerrarlos. En las vecindades los propietarios debían hacer lo mismo. ${ }^{24}$

El Ayuntamiento celebró diversos arreglos con contratistas privados para que se encargaran de instalar y manejar el servicio. Se les delegaba parte del trabajo a cambio de un pago acordado, y bajo ciertos lineamientos de funcionamiento y distribución determinados por la autoridad ciudadana. En 1861, el empresario que firmaba el contrato adquiría el compromiso de costear los gastos del mantenimiento de los faroles y sus lámparas, de reponerlos si hiciere falta, de pagar los sueldos de los empleados encendedores y de proveer sus faroles portátiles. También sería su responsabilidad corregir con prontitud los defectos en la cantidad de luz, y aquellos debidos a la mala calidad del gas, y mantendría funcionando el servicio desde las oraciones de la noche hasta la madrugada siguiente.

En las noches de luna sólo se encenderían los faroles "las horas necesarias antes y después de la llena para suplir con la luz artificial el resto del tiempo en que aquélla falte durante sus variaciones", y también se encendería la noche en que la luna, por estar muy nublado, no alumbrara lo suficiente. En caso de que "alguna revolución" o una fuerte epidemia interrumpieran el tránsito de los caminos y le impidieran abastecerse de gas, tendría que suplir la carencia con el mejor aceite, "procu-

${ }^{24}$ AMO, ramo Policía, caja 14/83, año 1864; caja 26/95, año 1868. rando por los medios que sus conocimientos le sugieran que la falta no sea tan sensible". ${ }^{25}$

Por su lado, el Ayuntamiento le pagaría al empresario quincenalmente, y por adelantado, doce reales mensuales por la luz de cada farol. $Y$ en caso de que alguna "función de armas" causada por disturbios locales y políticos le impidiera al nuevo responsable encender el alumbrado público, la corporación no le dejaría desprotegido y sólo reduciría la tarifa de esas noches a la mitad. Además correría con las expensas de los faroles y enseres del ramo que resultaran rotos.

Finalmente, el firmante regalaba al Ayuntamiento doce grandes farolas "de nueva invención con quinqués de luz entera y bombillas de cristal", obligándose a ponerlas en los lugares que se le indicaran, pero manteniendo sólo a dos de ellas ardiendo desde la media noche hasta el amanecer. Si como ofrecía, la luz de esas nuevas lámparas era "excesiva", entonces el Ayuntamiento podría disponer del sobrante para aprovecharlo "en otra parte". También se comprometía a ir regalando los faroles que progresivamente se fueran necesitando para el aumento del alumbrado, siempre y cuando no excedieran de cinco cada mes. El Ayuntamiento no pagaría más que por esa cantidad. ${ }^{26}$

Se pretendía que se estrenara un nuevo tipo de luz de petróleo, y aunque no tenemos el dato exacto de cuándo se hizo el cambio de combustible,

25 AMO, ramo Alumbrado, caja 11/80, año 1861.

26 Ibid. 
el historiador orizabeño, José María Naredo, asegura que en 1877 las lámparas callejeras ardían con "gas petróleo". En ningún lado aparece consignado que el cambio representara un salto técnico verdaderamente innovador, ni que implicara obras públicas mayores o reordenamientos urbanos de ningún tipo.

Así que, por lo visto, el alumbrado de las calles orizabeñas, organizado por vez primera en los años veinte, había ido mejorando, pero sólo acompasadamente y sin cambios espectaculares hasta casi terminado el siglo, cuando la llegada de la electricidad y los primeros focos de arco empezarían la verdadera revolución del ramo. Las luces de aceite y petróleo se extendieron por todo el casco urbano, pero nunca, hasta la irrupción de la iluminación eléctrica, alcanzaron a los barrios periféricos de la ciudad, agrícolas en gran parte, y con pocos habitantes que, además, eran pobres.

\section{ESPACIO, FINANZAS Y ADMINISTRACIÓN}

Para ambos servicios públicos, el del agua corriente y el de la iluminación callejera, la falta de dinero para administrar, ampliar e innovar una infraestructura que siempre se quedaba corta ante las exigencias de una ciudadanía cada vez más demandante, fue la cantaleta de siempre en el Cabildo.

Pero, ¿quiénes exigían? ¿Quiénes eran esos ciudadanos que se sentían con el derecho a reclamar cumplimientos al gobierno de la ciudad?

Desde luego no eran los marginados, los pobres desheredados de Oriza- ba. Todavía no corrían los tiempos en que esos relegados habitantes de las ciudades, convencidos de poder aspirar a las comodidades que la tecnología de la época podía ofrecer, presionaran para obtener la dotación de servicios que otros sí disfrutaban.

Reclamaban, claro está, los que bien o mal contaban con los servicios y se desesperaban con sus deficiencias y limitaciones. Y no eran tantos. En 1870 apenas 278 fincas urbanas pagaban pensiones anuales por recibir alguna "paja" de agua, cuando desde hacía 30 años ya se reportaban más del millar de casas de cal y canto en la ciudad, sin contar las chozas metidas en los solares del cinturón agrícola orizabeño. $Y$ de alrededor de 20000 habitantes, en ese mismo año sólo 410 propietarios estaban obligados a la pensión por el alumbrado callejero. ${ }^{27}$

Desde luego eran pocos. Pocos y con un acomodo bien definido sobre el territorio de la ciudad. El agua corriente y la iluminación nocturna se hallaban extendidas por todo el casco central, ahí donde los edificios se tocaban uno a otro en un continuo de construcciones, y sólo alargándose un poco sobre el eje vial principal y los que llevaban a polos importantes en la vida de Orizaba, como eran la fábrica de Cocolapan, el oratorio de San Felipe Neri o la nueva alameda.

En donde las casas alternaban con solares llenos de verde, sólo se presentaban algunos casos puntuales y siempre cercanos a este distrito nuclear. En la franja cultivada de los suburbios con

27 AMO, ramo Hacienda, caja 32/101, año 1870 . 


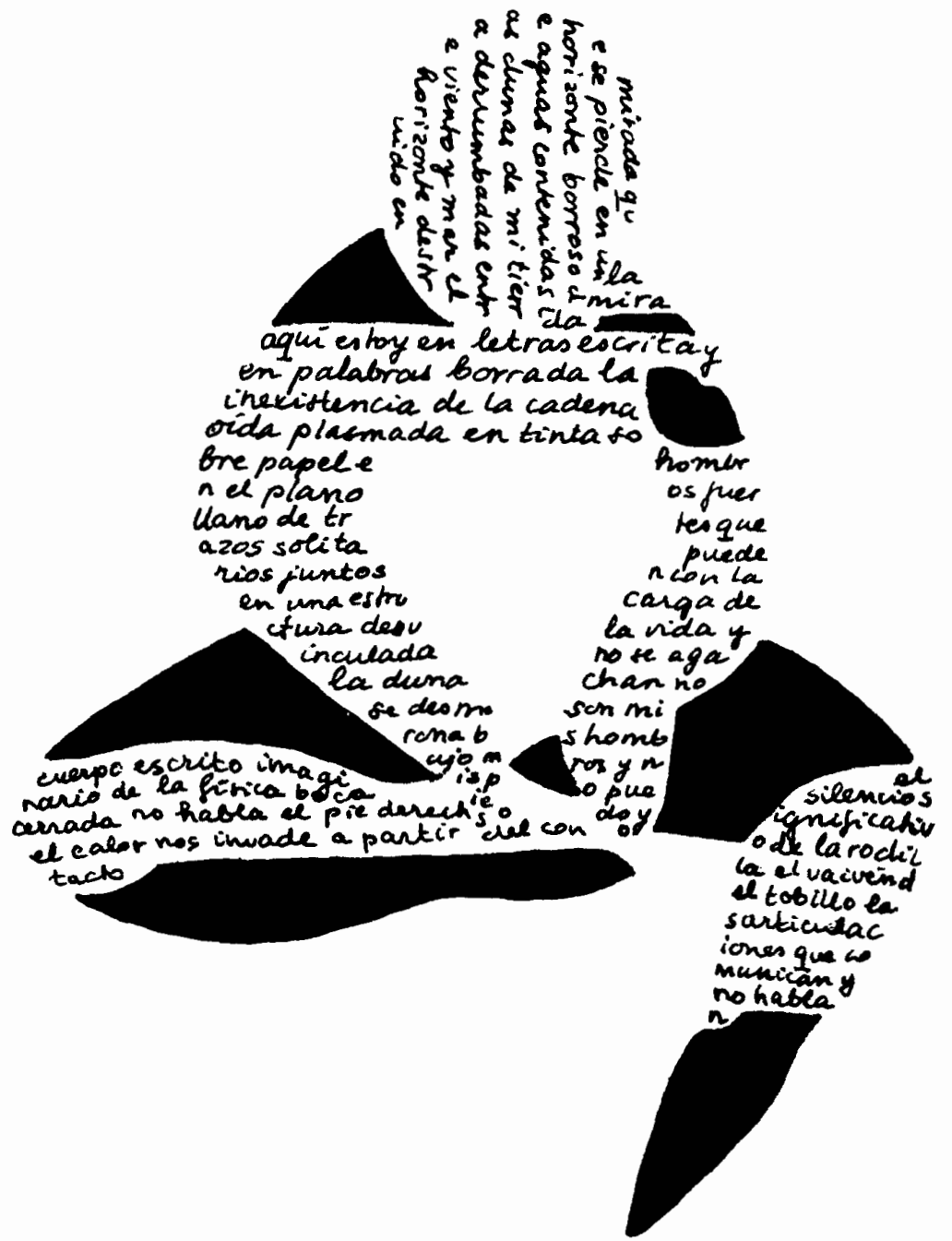


jacales de habitantes pobres, ninguno (véanse las figuras 1,2 y 3 ). ${ }^{28}$

Si consideramos que alejándonos del corazón urbano la densidad de población disminuía rápidamente, esa dimensión espacial tiene una lógica evidente. Sin embargo, si bien es cierto que disminuía la población, no debemos menospreciar el hecho de que ésta también era de más escasos recursos.

Eso nos lleva a reflexionar sobre la distribución del bienestar, y en cómo influye en ella la fuerza económica de ciertos grupos y personas, y su capacidad para presionar social y políticamente.

El asunto tiene importantes implicaciones de organización territorial de las estructuras urbanas. Como los propietarios de los lotes y los edificios deben retribuir a los ayuntamientos por la iluminación de una calle, por su pavimentación, o por la construcción de cañerías que les surtan de agua potable, son los vecindarios con mayor posibilidad para pagar los que concentran la instalación o modernización de los servicios públicos. Pero, además, no hay que olvidar que normalmente la gestión urbana se encuentra en manos de las clases económicamente dominantes, quienes ejerciendo el poder local, procuran retrasar los gastos públicos de orden social o de mejoramiento de las zonas marginales, al tiempo que los enfocan hacia los lugares que habi$\tan y$ hacia las actividades de mayor beneficio económico. ${ }^{29}$

${ }^{28}$ lbid.

${ }^{29}$ Christine Rosen, basándose en sus estudios sobre ciudades estadunidenses, hace comentarios interesantes al respecto; Rosen, "Infrastructural", 1986.
En nuestro caso orizabeño, como resultaría casi sin excepción en cualquier ciudad mexicana que quisieramos tomar como ejemplo, la ubicación central de los servicios nos habla claro de cuáles eran los espacios de privilegio al interior de las ciudades. Y también nos dice que, aunque haya habido más o menos crecimiento e innovación en los diversos ramos de servicios, los cambios reafirmaban una estructura urbana heredada del régimen colonial.

Nos referimos a la estructura en la que los centros alrededor de la plaza concentraban todas las representaciones del poder, eran los sitios de residencia de los dueños del dinero y, en consecuencia, en ellos se materializaban mayormente los esfuerzos por mejorar el funcionamiento y la imagen de la ciudad. Un centro contrapuesto a unas periferias que no contaban con equipamientos: ni se surtían de agua corriente, ni estaban iluminadas por las noches, ni tenían un tendido de acequias, ni sus polvorientas o enlodadas calles eran mantenidas en buen estado.

Sin embargo, si las nuevas infraestructuras y alcances de los servicios no favorecieron todavía desequilibrios mayores en los usos del suelo, como después lo harían cuando las posibilidades tecnológicas y de transporte empujaran a las oligarquías a buscar nuevos acomodos residenciales exclusivos y segregados hacia las periferias urbanas, sí estuvieron ligados a la transformación en las formas de concebir y gobernar la ciudad.

En la América colonial los servicios estuvieron siempre encomendados a los municipios tal cual lo habían estado desde la edad media en Europa. 


\section{SECUENCIG}

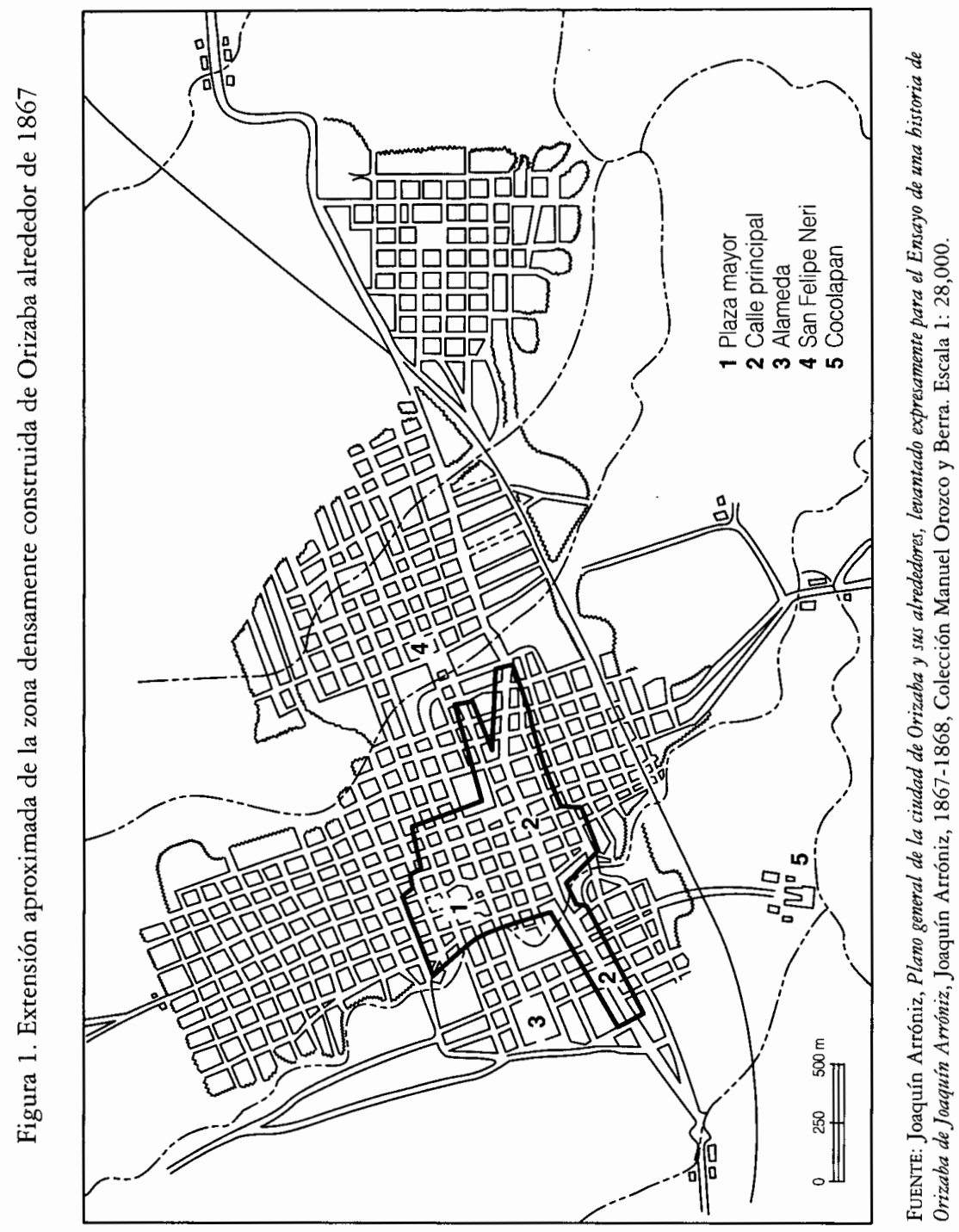




\section{SECUENCIA}






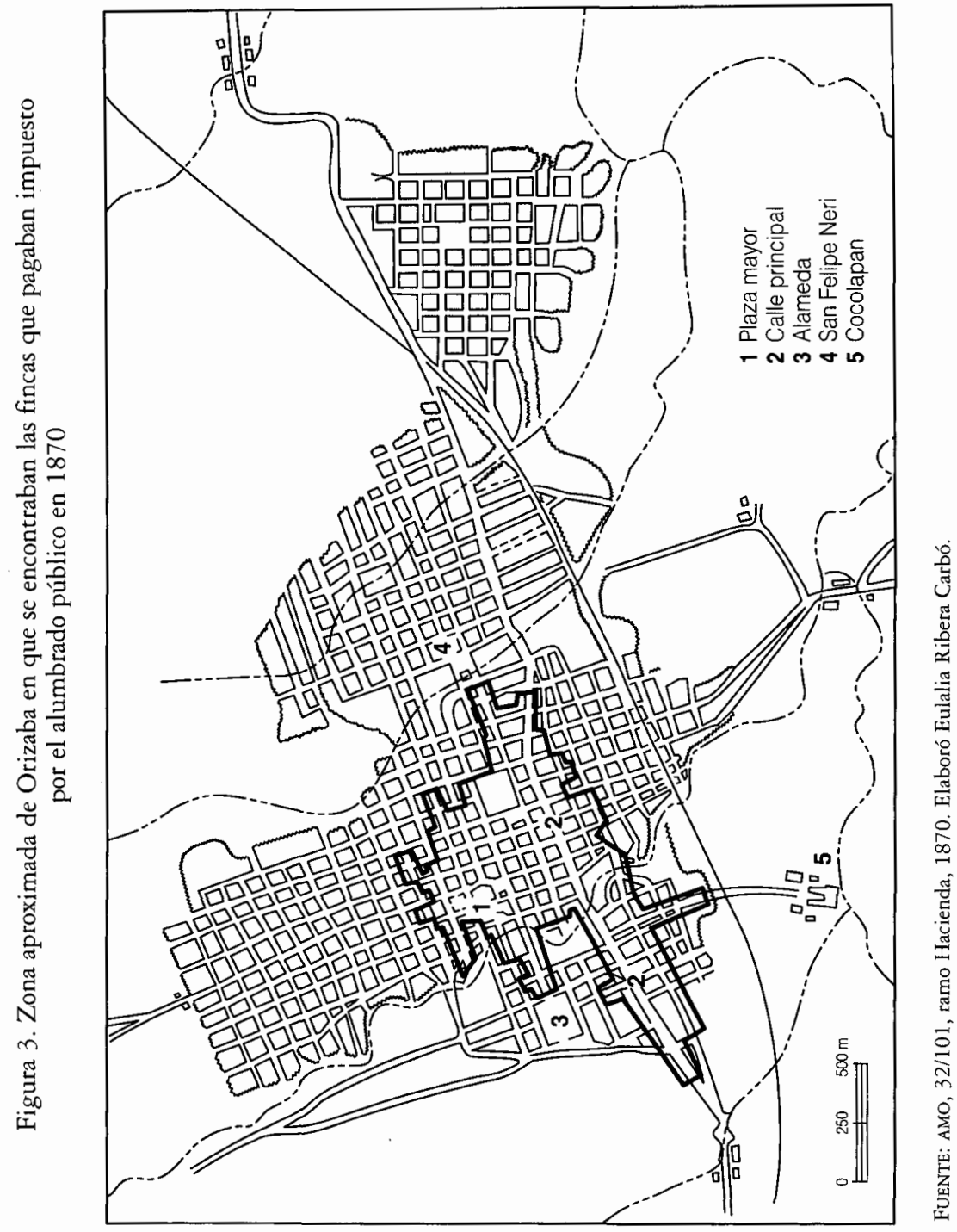


Pero en el siglo XIX, ante la renovación y la complejidad creciente de los sistemas de abastecimiento de agua, de alumbrado o de sanidad, los ayuntamientos se vieron incapacitados para proveer de ellos a los ciudadanos, más que nada por la dificultad para contar con los recursos para lograrlo.

El problema del financiamiento adquiere mayor dimensión, porque después de las revoluciones burguesas, cuando las ideas ilustradas habían permeado ya las conciencias y estaban incorporadas al pensamiento político de los grupos en el poder, los servicios públicos se fueron concibiendo como un bien que debía llegar a la sociedad en su conjunto, y poco a poco se fueron incluyendo en los programas de buen gobierno de los cabildos del mundo entero.

Pero la falta de capital, más o menos grave en todas las ciudades decimonónicas, imposibilitaba la instalación de las infraestructuras urbanas que se hacían "imprescindibles" con la modernidad, aun en el caso de existir la tecnología y la voluntad política para hacerlo, y aun cuando en la teoría, el sistema fiscal urbano, con la posibilidad de aumentar impuestos y crear otros nuevos, debía dar flexibilidad de acción a las finanzas municipales para hacer inversiones que las más de las veces no se prestan para lucrar, como es el caso de muchas de las infraestructuras y los servicios públicos. ${ }^{30}$

30 Jon Teaford elabora unas buenas reseñas y críticas a algunos trabajos de historia urbana sobre servicios municipales en ciudades estadunidenses durante el siglo XIX. Teaford, "Technology", 1987.
Lo cierto es que siempre hacía falta dinero. Al respecto, las discusiones en torno al financiamiento son interesantes. Hasta dónde debía pagar el Ayuntamiento por las mejorías y hasta dónde los vecinos que se beneficiarían de ellas. Orizaba ejemplifica este conflicto general que nos acerca al proceso de modernización en torno al concepto del servicio público como una obligación de estado. El Ayuntamiento se confirma como el propietario, pero junto con los ciudadanos comparte la responsabilidad de crear un tipo de infraestructura, que con el tiempo, acabará por ser, no sólo en Orizaba, quehacer del aparato de la administración pública en arreglo con compañías constructoras concesionadas o contratadas. ${ }^{31}$

Efectivamente éste es el marco en el que hay que situar la presencia de empresas privadas, a las que el municipio encomienda la provisión de algunos servicios $-y$ que normalmente son los que permiten ciertos márgenes de ganancias- negociando contratos que les resulten atractivos, igual una compañía constructora de cualquier gran ciudad del mundo, que los modestos Miguel López o don Sabino Ambrís, con quienes el Honorable Ayuntamiento de Orizaba celebraba respectivos acuerdos para el manejo del alumbrado de la ciudad. ${ }^{32}$

Si hemos de comparar el caso orizabeño con ottos que tenemos a la mano, como el de Oaxaca y el de la ciudad de

\footnotetext{
31 Sobre el origen y las características del contratismo en la ciudad de México es interesante el trabajo de Priscilla Connolly, "Desagüe", 1999.

32 AMO, ramo Alumbrado, caja 6/73, año 1857; caja 11/80, año 1861 .
} 
México que han sido estudiados por Carlos Lira y Ariel Rodríguez, ${ }^{33}$ salta a la vista que en los tres la administración del servicio de agua durante el siglo XIX fue atribución directa de los ayuntamientos. En los años ochenta, en la capital se hizo algún intento por financiar el sistema de agua potable por una vía no fiscal a través de ventas de acciones a suscriptores. Fracasó. También se trabajó en un proyecto para arrendar su control y administración a un empresario privado; pero el proyecto generó tal polémica que la consecuencia fue la consolidación del monopolio del gobierno local sobre la construcción de la obra física y la administración del servicio. ${ }^{34}$ Incluso después de que en 1903 se redactara un reglamento para los nuevos fraccionamientos que ensanchaban a la ciudad por los cuatro costados, y en el que se obligaba al concesionario constructor de una colonia a dotarla de agua potable y atarjeas con la promesa del futuro reembolso por parte del Ayuntamiento, la realidad fue que, a excepción de las colonias Roma, Condesa, Juárez y Cuauhtémoc, destinadas a gente con un alto poder adquisitivo, el reglamento nunca fue respetado y el Ayuntamiento acabó siendo el encargado de la provision del agua. ${ }^{35}$

En Oaxaca, después de la desamortización y nacionalización de los bienes eclesiásticos, el municipio le arrebató a los conventos el control que tenían sobre parte del abasto de agua a

33 Lira, "Obra", 1999; Rodríguez, "Gobierno", 1999.

34 Rodríguez, "Gobierno", 1999.

35 Morales, "Expansión", 1978, pp. 197-199. particulares, de la misma forma que en Orizaba, a petición del Ayuntamiento, el Ministerio de Hacienda acordó, en junio de 1861 , darle al municipio la propiedad, el uso y el disfrute del agua y el acueducto del extinguido convento del Carmen. Durante el porfiriato, también en la antigua Antequera, fueron presentados al Ayuntamiento varios proyectos, que ingenieros en plan privado habían diseñado para perfeccionar el suministro del líquido a la ciudad. Todos fracasaron y, según Carlos Lira, fue la comisión del agua del municipio quien logró expandir el abasto a gran número de casas-habitación y a edificios públicos que no contaban con él. 36

Los argumentos esgrimidos durante las negociaciones entre cabildos y particulares convergen, por lo visto, en la reafirmación del Ayuntamiento como la institución encargada de velar por el bien público. Por encima de los afanes de lucro que encuentran puertas abiertas con la modernización de infraestructuras y servicios, está lo que, en palabras de Rodríguez Kuri, es "una economía moral del servicio". Y de ésta, sólo puede encargarse el cuerpo municipal. ${ }^{37}$

Sin embargo, el manejo del alumbrado se encamina por otro rumbo, aunque también con paralelismos evidentes en los tres centros urbanos. En todos, el servicio a cargo del municipio acaba por ser concesionado a contratistas particulares antes o después durante la segunda mitad de la centu-

\footnotetext{
36 Lira, "Obra", 1999, p. 244; Амо, ramo Aguas, caja 11/80, año 1861.

37 Rodríguez, "Gobierno", 1999, p.174.
} 
ria. En Orizaba, la propiedad de la infraestructura de iluminación con aceite y "gas-petróleo" siguió en manos de la corporación, pero fue un contratista el encargado de mantenerla en buen estado y de hacerla funcionar a cambio de un pago quincenal por parte del Ayuntamiento. Cuando en 1891 se inauguró el primer sistema de iluminación eléctrica, lograda por impulso de la nueva forma de energía que se aplicó en la fábrica de hilados de Cocolapan, el servicio funcionó por medio de un contrato firmado entre el Ayuntamiento y los dueños de la empresa textil. 38

En Oaxaca, a finales de la década de 1890 , una compañía particular se hizo propietaria de la planta eléctrica $y$, en los mismos años, en la ciudad de México, el Ayuntamiento dio autorización para concesionar la electrificación a una empresa de capital extranjero y romper lo que consideraba como el monopolio que otra compañía ejercía sobre el alumbrado de gas y trementina. ${ }^{39}$

Aparentemente no está consignada ninguna argumentación que plantee la propiedad pública del ramo como una necesidad de interés colectivo, pero lo cierto es que hay mucho por estudiar. Nuevos trabajos que aborden los detalles de los procesos de innovación en los servicios públicos de las ciudades mexicanas del siglo XIX, permitirán elaborar conclusiones más categóricas en torno a las formas y a los conceptos en

\footnotetext{
${ }^{38}$ Naredo, Estudio, 1898. Las condiciones de la electrificación de Orizaba durante el porfiriato todavía no han sido estudiadas.

39 Lira, "Obra", 1999, pp. 247, 248; Rodríguez, "Gobierno", 1999, pp. 177-178.
}

que se gestó la modernización urbana decimonónica. ¿Cómo intervinieron en cada caso los intereses de las oligarquías urbanas, de los gobiernos locales, estatales y federal, y de los grandes capitales en la construcción y comercialización de los servicios de las ciudades? ¿Cómo se articulan estos actores en los engranajes de la administración, de los mercados y en el marco políticoinstitucional de su tiempo? ¿Cómo y por qué se define el carácter estratégico de un ramo público para alcanzar el bien común?

Son muchas preguntas que aún hay que responder. Atrevámonos, sin embargo, y a pesar de lo que falta por estudiar, a volver al principio de este trabajo para retomar la frase con la que empezamos, y decir que Orizaba no era tan diferente. No lo era, porque si en Orizaba se introducía un sistema de agua potable y corriente, se ampliaba y se intentaba, bastante infructuosamente por cierto, innovar en el de alumbrado nocturno, y el Ayuntamiento se enfrentaba a los problemas que llevaba aparejados la complejidad creciente de los servicios públicos, el proceso en esencia y guardados todos los matices, proporciones y particularidades importantes, era equivalente al de cuando en la ciudad de México se demolían los acueductos coloniales para instalar tubos de hierro que canalizaran y repartieran el agua, se discutía el sentido ético de los servicios y el bien público y se hacían tentativas para otorgar el alumbrado en concesiones privadas; cuando las autoridades urbanas de Londres y París pavimentaban, drenaban e iluminaban el espacio callejero, o cuando en Chicago y Boston los mu- 
nicipios trabajaban en la instalación de infraestructuras para la distribución del agua corriente. ${ }^{40}$

Era parecido porque, finalmente, a pesar de todas las especificidades propias de cada realidad histórica y geográfica concreta, el espacio urbano refleja la organización y las formas de convivencia de la sociedad, y en el siglo xIX el mundo se homogeneizaba al son que tocaban las grandes potencias industrializadas en expansión, que exportaban e imponían formas de trabajo, tecnologías, conceptos y normas de comportamiento, modas y gustos estéticos.

Las grandes transformaciones urbanas decimonónicas representan bien esa incorporación de todos a un sistema económico globalizado, en el que aquellos que pueden incidir sobre el espacio, lo moldean para adecuarlo a las exigencias de las nuevas formas de producción de riqueza, de distribución y de consumo, que integran a todos los pueblos en una jerarquía dictada por la división internacional del trabajo.

Por ello, aun sin mensopreciar las diferencias que distinguen a cada lugar y circunstancia, hay que reconocer que la dinámica del nuevo capitalismo mundial enmarca las formas en que el poder, aquí y allá, se esfuerza por ordenar el espacio de acuerdo a sus intereses económicos y lo maquilla para conseguir una imagen de ciudad, adecuada a sus principios jurídicos e ideológicos.

40 Para esos casos véase: Bedarida y Surcliffe, "Street", 1980; Gortari y Hernández, Memoria, 1988; Rodríguez, "Gobierno", 1999; Rosen, "Infrastructural", 1986.
Modernidad económica, modernidad administrativa, modernidad conceptual y modernidad estética, se reflejan en la modernidad espacial de los entornos urbanos. $Y$ a esas modernidades contribuyeron, sin lugar a dudas, a la nueva organización e infraestructura de los servicios públicos en el siglo XIX.

\section{ARCHIVo}

AMO Archivo Muncipal de Orizaba

\section{BIBLIOGRAFÍA}

-Arróniz, Joaquín, Ensayo de una bistoria de Orizaba, Editorial Citlaltépetl, México, 1980 (Colección Suma Veracruzana, Serie Historiografía).

-Baz, Gustavo y Gallo, Eduardo L., Historia del ferrocarril mexicano. Riqueza de México en la zona del Golfo a la Mesa Central, bajo su aspecto geológico, agrícola, manufacturero y comercial, Editorial Innovación, México, 1977, edición facsimilar.

-Bedarida, François \& Sutcliffe, Anthony, "The street in the structure and life of the city: reflections on Nineteenth century London and Paris", Journal of Urban History, vol. 6, núm. 4, agosto, 1980, pp. 379-396.

-Connolly, Priscilla, "El desagüe del Valle de México. Política infraestructural, contratismo y deuda pública" en Sandra Kuntz y Priscilla Connolly, Ferrocarriles y obras públicas, Instituto Mora/El Colegio de Michoacán/El Colegio de México/Instituto de Investigaciones Históricas-UNAM, México, 1999 (Lecturas de Historia Económica Mexicana).

-Geisse, G. G., "Tres momentos históricos en la ciudad hispanoamericana del siglo 
XIX", Revista Latinoamericana de Estudios Urbano Regionales, Instituto de Estudios Urbanos de la Facultad de Arquitectura y Bellas Artes de la Pontificia Universidad Católica de Chile, vol. xiII, núm. 38, diciembre, 1986, Santiago.

-Gortari Rabiela, Hira de y Regina Hernández, Memoria y encuentros: La ciudad de México y el Distrito Federal (1824-1928), Departamento del Distrito Federal/Instituto de Investigaciones Dr. José María Luis Mora, México, 1988.

-Halperin Dongui, Tulio, "Las ciudades hispanoamericanas (1825-1914). El contexto económico social", Revista Interamericana de Planificación, vol. XIV, núm. 55-56, septiembre-dicembre, 1980.

-Lira, Carlos, "Obra y servicios públicos en Oaxaca, 1876-1911", en Sandra Kuntz y Priscilla Connolly, Ferrocarriles y obras públicas, Instituto Mora/ El Colegio de Michoacán/ El Colegio de México/ Instituto de Investigaciones Históricas-UNAM, México, 1999 (Lecturas de Historia Económica Mexicana).

-Morales, María Dolores, "La expansion de la ciudad de México en el siglo XIX: el caso de los fraccionamientos" en Alejandra Moreno Toscano, Ciudad de México: ensayo de construcción de una bistoria, SEP/INAH, México, 1978 (Colección Científica. Historia, 61)

- Naredo, José María, Estudio geográfico, bistórico y estadístico del cantón y de la ciudad de Orizaba, Imprenta del Hospicio, Orizaba, 1898.

-Rodríguez Kuri, Ariel, "Gobierno local y empresas de servicios: la experiencia de la ciudad de México en el porfiriato" en Sandra Kuntz y Priscilla Connolly, Ferrocarriles $y$ obras públicas, Instituto Mora/El Colegio de Michoacán/El Colegio de México/Instituto de Investigaciones Históricas-UnAm, México, 1999 (Lecturas de Historia Económica Mexicana).

-Rosen Meisner, Christine, "Infrastructural improvement in the nineteenth-century cities: a conceptual framework and cases", Journal of Urban History, vol. 12, núm. 3, mayo, 1986, pp. 211-256.

-Segura, Manuel de, "Apuntes estadísticos del distrito de Orizava, formados el año de 1839", Boletín de la Sociedad Mexicana de Geografía y Estadística, t. 4, 1854, México, pp. 3-71.

-Teaford, Jon C., "Technology, expertise, and municipal services, 1860-1940", Journal of Urban History, vol. 10, núm. 3, mayo, 1987, pp. 319-328.

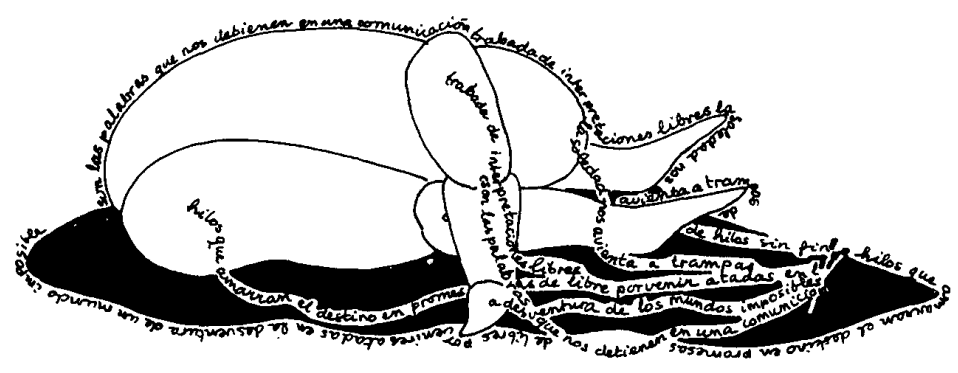

MODERNIDAD Y SERVICIOS PÚBLICOS 